\title{
Bioreactor for wastewater treatment
}

\author{
Artem Kulakov ${ }^{1, *}$ and Nikolay Makisha ${ }^{2}$ \\ ${ }^{1}$ Vologda State University, Department of water supply and wastewater treatment,15, Lenina str., \\ Vologda, Russia, 160000 \\ ${ }^{2}$ Moscow State University of Civil Engineering, Research centre "Water supply and wastewater \\ treatment", 26, Yaroslavskoye shosse, Moscow, Russia, 129337
}

\begin{abstract}
The article touches upon the efficiency of small capacity wastewater treatment plant for industrial sewage. Current operation scheme fails to meet existing regulation requirements due to several drawbacks. The article describes a technology for wastewater treatment and the construction of bioreactor to implement the scheme above. The technology includes averaging tank with preliminary mechanical treatment and bioreactor with floating feed. This provides the efficiency of removal of organic compounds and nutrients: BOD $-96 \%$, nitrogen $-99 \%$, phosphorus $-89 \%$.
\end{abstract}

\section{Introduction}

The difficult engineering task is to achieve environmental standards in small wastewater treatment plants (WWTP). Only $3 \%$ of small WWTP in Vologda region (Russia) meet required concentrations for outlet phosphorus, and 5\% for ammonia nitrogen [1].

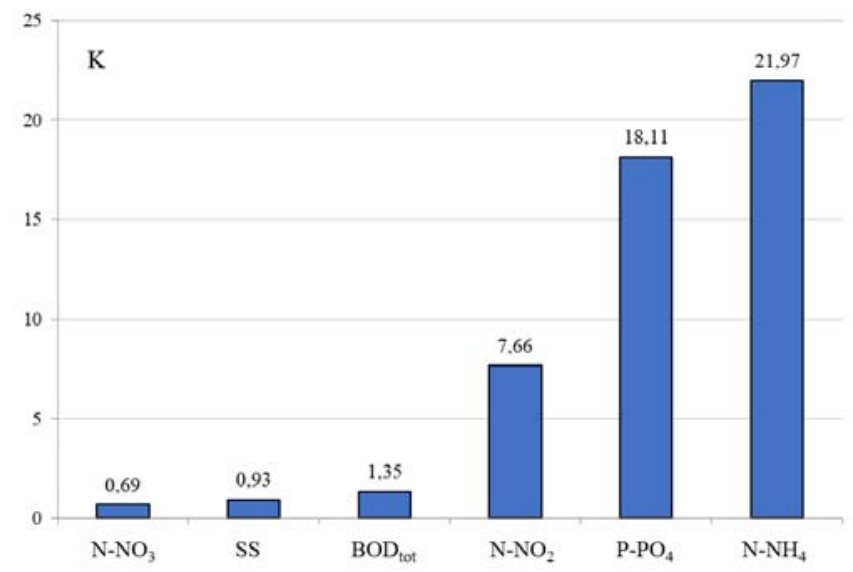

Fig. 1. Factor of excess of limited concentrations in treated water.

*Corresponding author: artem.a.kulakov@gmail.com 
These indicators also show maximum ratio of outlet concentration to required values among the main parameters: total biochemical oxygen demand $\left(\mathrm{BOD}_{\mathrm{tot}}\right)$, suspended solids (SS), ammonia nitrogen $\left(\mathrm{N}-\mathrm{NH}_{4}\right)$, nitrite nitrogen $\left(\mathrm{N}-\mathrm{NO}_{2}\right)$, and nitrate nitrogen $\left(\mathrm{N}_{-} \mathrm{NO}_{3}\right)$; phosphorus phosphate $\left(\mathrm{P}-\mathrm{PO}_{4}\right)$ (Figure 1).

Low efficiency of small WWTP happens due to their features and shortcomings [2]:

- Technology (physical and moral depreciation, violation of operating conditions, the hydraulic underload/overload, high unevenness in the flow of wastewater).

- Operation (lack of staff, the spatial dispersion of objects, low level of equipment).

- Economy (high unit operating and capital costs).

- Limited technical and financial resources in rural areas.

All of the above allows us to distinguish small WWTP in a separate large group of objects that require an individual approach to modernization and operation.

\section{Materials and methods}

The article has a focus on small WWTP that treat domestic sewage at industrial sites.

Normally technological scheme includes:

1. Multi-chamber aeration tank with attached biomass:

- Large reactor with floating media (Figure 2b)

- Reactor with block loading (Figure 2a)

- Reactor with small floating media (Figure 2c)

2. Coagulation chamber

3. Flocculation chamber

4. Secondary clarifier with thin-layer modules

5. Sludge dewatering unit

6. Disinfection facility

a)

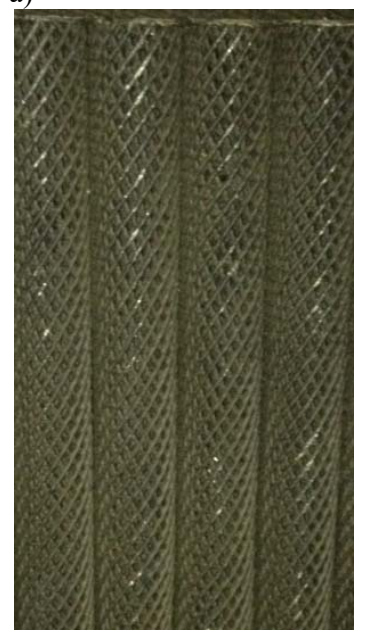

b)

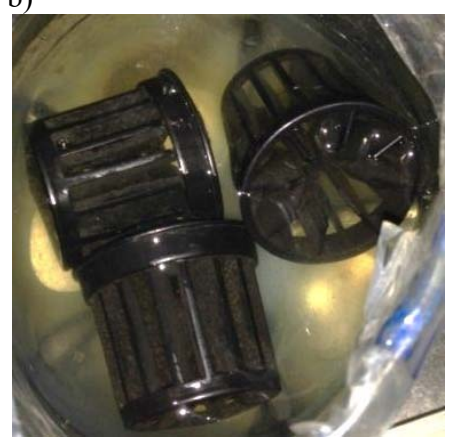

c)

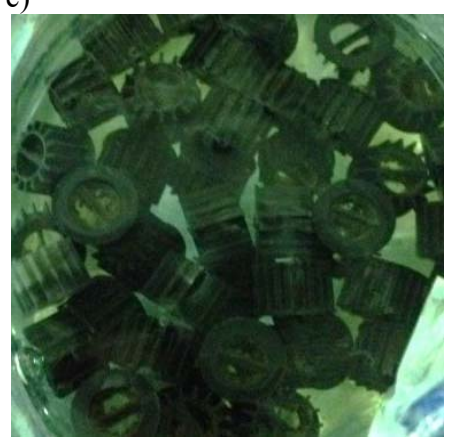

Fig. 2. Types of feed: a) block media; b) large floating media; c) small floating media.

WWTP capacity is 40 cubic meters per day; aeration reactor volume is 6.5 cubic meters that means that HRT is 4 hours. According to WWTP documentation is has to provide nitrification and denitrification with phosphorus removal. However, only aerobic mode is ensured with partial oxidation of organics and nitrification; denitrification is weak. Actual capacity is 10 cubic meters per day with significant season (Figure 3) and daily flow 
irregularity; actual HRT is 15.5 that might be enough for required biochemical processes $[3,4]$.

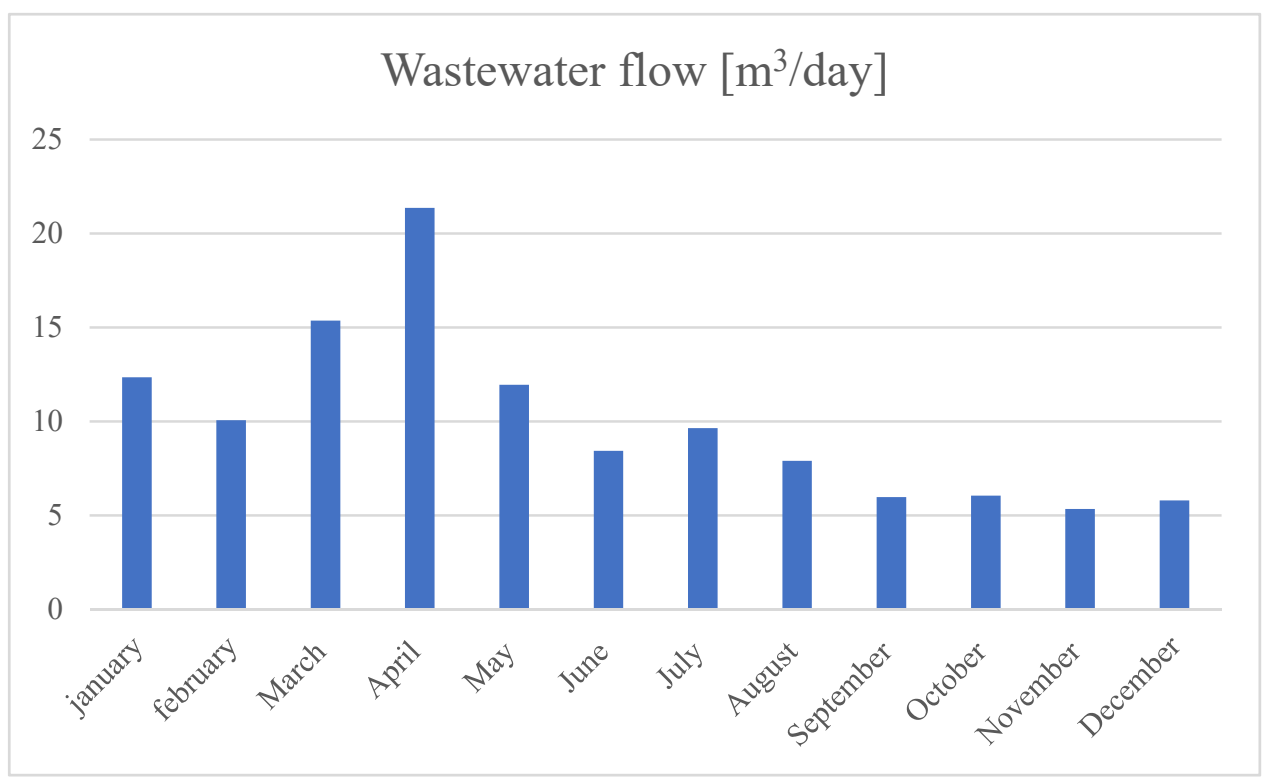

Fig. 3. Annual flow of wastewater.

Analyses of treated water samples (Table 1) showed occasional excess of requirements for nitrogen compounds, phosphorus and BOD.

Table 1. Control indicators for WWTP.

\begin{tabular}{|l|c|c|c|c|}
\hline \multirow{3}{*}{ Indicator } & \multicolumn{4}{|c|}{ Concentrations [mg/l] } \\
\cline { 2 - 5 } & \multicolumn{2}{|c|}{ Before reconstruction } & \multicolumn{2}{c|}{ After reconstruction } \\
\cline { 2 - 5 } & In & Out & In & Out \\
\hline TSS & 80 & 17 & 65 & 8.6 \\
\hline BOD & 86 & 5.2 & 89 & 3.5 \\
\hline $\mathrm{N}_{5}-\mathrm{NH}_{4}$ & 41 & 6.6 & 64 & 0.35 \\
\hline $\mathrm{N}-\mathrm{NO}_{2}$ & $<0.03$ & 0.32 & $<0.03$ & 0.01 \\
\hline $\mathrm{N}-\mathrm{NO}_{3}$ & 0.15 & 18 & 0.15 & 10.1 \\
\hline $\mathrm{P}_{3} \mathrm{PO}_{4}$ & 2.5 & 0.7 & 2.2 & 0.25 \\
\hline
\end{tabular}

Table 2. Concentrations of dissolved oxygen in WWTP.

\begin{tabular}{|c|c|c|c|c|c|c|}
\hline & Reactor 1 & Reactor 2 & Reactor 3 & Reactor 4 & $\begin{array}{c}\text { Floculation } \\
\text { chamber }\end{array}$ & Clarifier \\
\hline $\mathrm{CDO}[\mathrm{mg} \backslash \mathrm{l}]$ & $3.7-6.9$ & $5.1-6.5$ & $5.4-7.9$ & $6.2-7.8$ & $6.5-8.1$ & $3.5-7.3$ \\
\hline
\end{tabular}

The concentrations of dissolved oxygen (CDO were) estimated. Increased CDO mean inhibition of denitrification and glut of oxygen that leads to excessive operation costs and energy consumption. Technical survey also reveals following operation difficulties:

1. Surface of feed materials immobilize almost no biofilm, which leads to insufficient efficiency of wastewater treatment.

2. Uneven (peak-flow) supply of wastewater for treatment is highlighted, which leads to peak overloads of biocenosis and biomass leaching from the plant with purified water. General hydraulic underload of WWTP is observed. 
3. There was excessive intensity of aeration noted which could cause a decrease in the efficiency of attachment of microorganisms and inhibition of denitrification processes.

4. At peak waste water flows, the floating load is removed from the reactors.

5. Block loading is clogged with garbage due to the lack of a grate and clogged with sludge as a result of a dense arrangement in the reactor.

6. Sludge is floating in the secondary settler and following removed out of it.

7. Identified irregular supply of the coagulant and the increase in the concentration of phosphates in effluents.

8. Technological units of the RSC are in working condition.

The upgrade measures that were applied are listed in Table 3.

Table 3. Operation improvement directions of WWTP.

\begin{tabular}{|c|c|c|}
\hline & Action & Result \\
\hline 1 & $\begin{array}{l}\text { Grid installation between the reactors with } \\
\text { smaller screens }\end{array}$ & Reduction of media flow-off \\
\hline 2 & $\begin{array}{l}\text { Tank control: } \\
\text { - Current conditions control; } \\
\text { - Cleaning of walls and restoration if needed. }\end{array}$ & $\begin{array}{l}\text { - } \quad \text { Removal of dirt on the walls that may } \\
\text { cause secondary pollution;; } \\
\text { - } \quad \text { Restoration of damaged parts of walls. }\end{array}$ \\
\hline 3 & Washing of media and thin-layer modules & $\begin{array}{ll} & \text { Washing of dead biomass on the media; } \\
\text { - } & \text { Increase of MLSS; } \\
\text { - } & \text { Reduction of biomass flow-away. }\end{array}$ \\
\hline 4 & $\begin{array}{l}\text { Adjustment of aeration system and } \\
\text { concentration of dissolved oxygen }\end{array}$ & $\begin{array}{ll}- & \text { Reduction of media washing intensity; } \\
- & \text { Improvement of oxygen mode. }\end{array}$ \\
\hline 5 & $\begin{array}{l}\text { Application of zones for nitrogen removal: } \\
\text { - Evaluation of new construction and its' } \\
\text { launch into service; } \\
\text { - Provision of anoxic and aerobic zones. }\end{array}$ & $\begin{array}{l}\text { - Provision of conditions for denitrification } \\
\text { and nitrification; } \\
\text { - Improvement of nitrogen removal } \\
\text { efficiency. }\end{array}$ \\
\hline 6 & $\begin{array}{l}\text { Internal recycling form aerobic to anoxic zone, } \\
\text { sludge recycle from secondary clarifier }\end{array}$ & Provision of conditions for denitrification \\
\hline 7 & $\begin{array}{l}\text { Adjustment of coagulant dosage system } \\
\text { (adding and mixing) }\end{array}$ & $\begin{array}{l}\begin{array}{l}\text { Improvement of phosphorus removal } \\
\text { efficiency }\end{array} \\
\end{array}$ \\
\hline 8 & Averaging tank installation & $\begin{array}{l}\text { - Prevention of media flow-away } \\
\text { - Reduction of load at biocenosis. }\end{array}$ \\
\hline 9 & $\begin{array}{l}\text { Installation of filters for tertiary treatment (if } \\
\text { necessary) }\end{array}$ & $\begin{array}{l}\text { - Prevention of biofilm flow-off; } \\
\text { - Stable and efficient treatment. }\end{array}$ \\
\hline
\end{tabular}

\section{Results}

The first tank of the facility was modified to a biofilter with sprinkler system to create anoxic conditions for denitrification. The internal nitrate-flow was also pumped here from the bioreactor. After the biofilter sewage subsequently goes through three steps of bioreactor. The second and the third tank of the facility was modified into bioreactors with floating media. The block media was taken away due to its low efficiency. After the bioreactors sewage goes to coagulation chamber, and then to thin-layer clarifier. A system for collection and pumping of sludge from secondary clarifier into bioreactor was assembled to prevent secondary contamination and excessive removal of sludge [5-7].

The facility was additionally equipped with an averaging tank needed for automated pumping of sewage for treatment that allows reducing of hydraulic load at the facility and creating good conditions for biomass [8]. Special nets were installed in bioreactors and coagulation chamber to prevent removal of floating media. A screen with $4 \mathrm{~mm}$ grit was installed on the inlet pipeline to remove large particles. Small particles of biofilm can be held 
in the systems with sand filters. Technological scheme is shown in the Figure 4, overview of the facility on the Figure 5. The facility showed stable work after the upgrade with necessary amount of biofilm on the floating media (Figure 6) and high efficiency of BOD, nitrogen and phosphorus removal $[9,10]$. Figure 7 shows how the nitrogen concentration changed in the reactors.

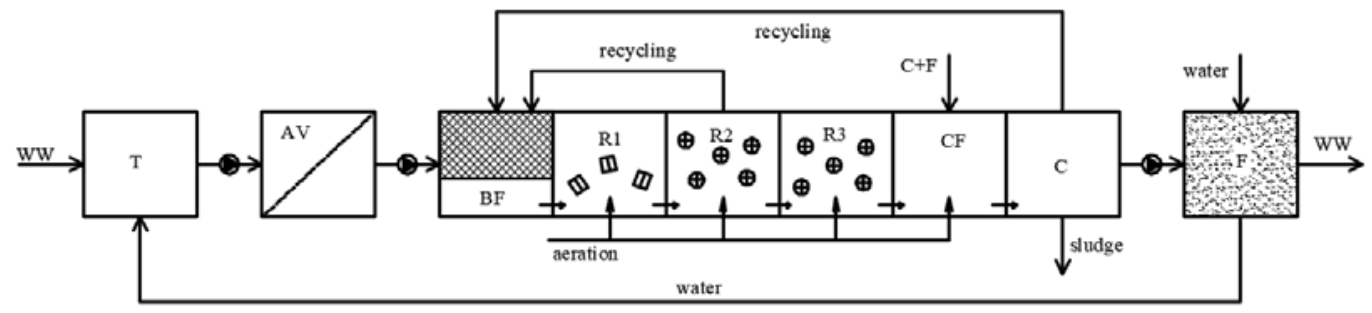

Fig. 4. Technological scheme: $\mathrm{T}$ - tank; AV - averaging tank with mechanical treatment (screens); BF - biofilter; R1, R2, R3 - bioreactors; CF - coagulation and flocculation chamber; C - Clarifier; F filter; WW - wastewater.

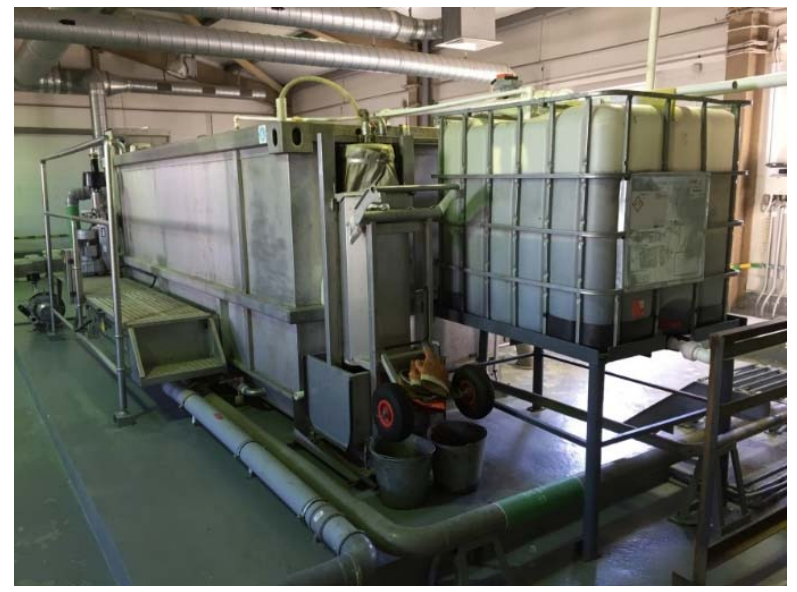

Fig. 5. Facility overview after the upgrade.

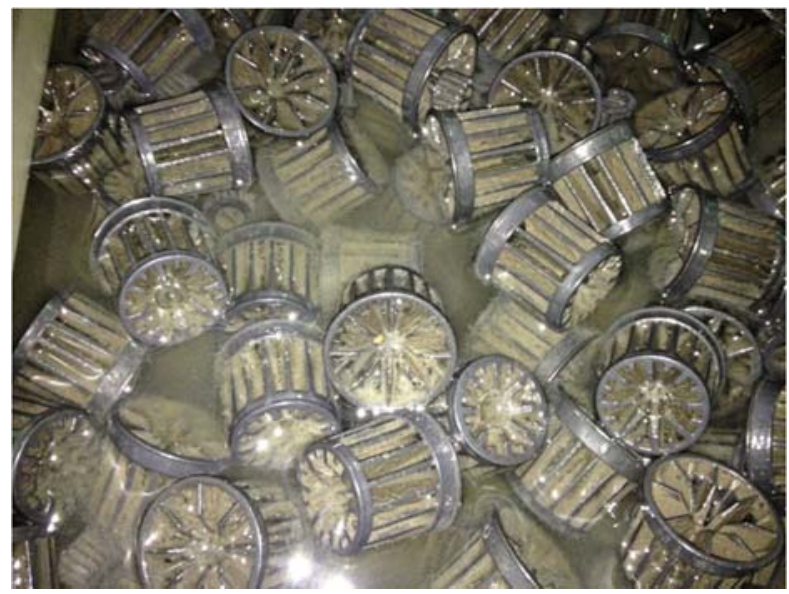

Fig. 6. Biofilm overview. 


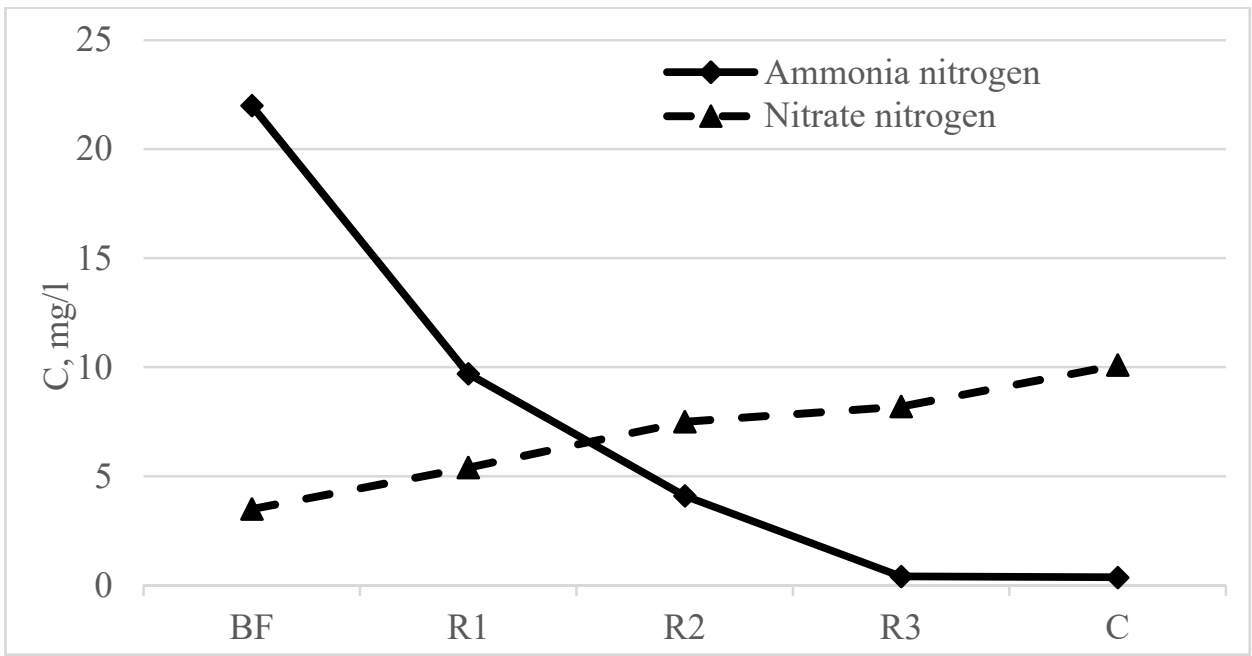

Fig. 7. Change of nitrogen concentration in the reactors.

\section{Conclusions}

1. Technological, operational and economic aspects that reduce the efficiency of their work have been highlighted.

2. The technology of small facility upgrade that provides $96 \%$-efficiency for BOD removal, 99\%-efficiency for ammonium removal and 89\%-efficiency for phosphates removal was evaluated.

3. Averaging tank was implemented to reduce load at biocenosis and to prevent garbage inlet into the facility.

The reported study was funded by the The Head Regional Shared Research Facilities of the Moscow State University of Civil Engineering

\section{References}

1. A.A. Kulakov, ViST, 5, 25-30 (2013)

2. A.A. Kulakov, Wat.Ecol, 1, 61, 26-40 (2015)

3. Zaletova N.A., Zaletov S.V., Int. J. of Appl. Eng. Res., 10, 23, 43873-43874 (2015)

4. N. Makisha, D.Semenova, MATEC Web of Conferences, 144, 04016 (2018)

5. I.Gulshin, MATEC Web of Conferences, 106, 07002 (2017)

6. I.Gulshin, IOP : Earth and Env. Sci., 90, 012198 (2017)

7. A.G. Pervov, A.P. Andrianov, DWT, 35, 1-3, 2-9 (2011)

8. E. Sherbina, N. Danilina, D. Vlasov, Int. J. of Appl. Eng. Res., 10, 22, 43131-43138 (2015)

9. N. Danilina, E3sconf, 6, 02001 (2016)

10. N. Makisha, E3sconf, 6, 01002 (2016) 